\title{
A literatura brasileira no exterior
}

\section{Joelma Santana Siqueira (Universidade Federal de Viçosa). Vivaldo Andrade dos Santos (Georgetown University).}

Pode-se dizer, em certo sentido, que a literatura brasileira se origina antes do Brasil e, por isso, alguns historiadores optam por chamar o momento inicial de "Literatura do Período Colonial" ou "Literatura Luso-brasileira", constituída por textos produzidos por escritores que se encontravam na colônia, como o Padre José de Anchieta, nascido nas Ilhas Canárias, autor, entre outros textos, d' $O$ Auto de São Lourenço, escrito em tupi, espanhol e português. Pertence a esse contexto o escritor Manuel Botelho de Oliveira, primeiro autor nascido na colônia a ter um livro publicado. Sua primeira obra se intitula Mal amigo e sua obra principal, Música do Parnaso, foi escrita em português, castelhano, italiano e latim, publicada em 1705, em Lisboa. Insere-se também nesse período da literatura luso-brasileira o poeta Tomás Antônio Gonzaga, nascido no Porto, Portugal, autor da obra Marília de Dirceu, publicada em 1792, em Lisboa, enquanto o autor encontrava-se exilado na África por causa de sua participação na Inconfidência Mineira. A obra foi impressa no Brasil em 1810, dois anos depois da chegada da imprensa ao país, em 1808, com a vinda da família real para a colônia. Pouco tempo após a independência política ocorrida em 1822, um grupo de escritores publicou, em Paris, no ano de 1836, a Revista Niterói, que, junto com a obra Suspiros poéticos e saudades, de Gonçalves de Magalhães, também publicada em Paris no ano de 1836, foi responsável por lançar as bases do Romantismo Brasileiro. Décadas depois, a Revista Novo Mundo foi lançada em Nova York, em 1870, e, semelhantemente à Revista Niterói, divulgou as bases de um novo momento da literatura brasileira, nesse caso, o

Gláuks: Revista de Letras e Artes -jul/dez $2020-$ Vol. 20, $N^{\circ} 2$ 
Realismo. Foi nessa revista que Machado de Assis publicou o célebre ensaio "Notícia da atual literatura brasileira - instinto de nacionalidade", em 1873.

As Letras produzidas no Brasil colônia estão historicamente ligadas às Letras Portuguesas. A despeito desse fato, a língua em comum assegura múltiplas aproximações entre as duas literaturas. Para exemplificar, lembremos o início da atuação do Professor Georges Le Gentil na Sorbonne, pois, de acordo com Sébastien Rozeaux, em 1919, o professor Georges Le Gentil foi encarregado de um curso de língua e literatura portuguesa, resultado de uma iniciativa do governo de Portugal; e em 1922, assumiu "também o primeiro curso de literatura brasileira, inaugurado cem anos após a proclamação da Independência por parte do Império brasileiro" ". Essa informação é interessante, sobretudo, se atentarmos para o que escreveu o professor Emérito da Universidade do Porto Arnaldo Saraiva (1999, p.7) a respeito da implementação dos estudos de literatura brasileira nas universidades portuguesas, ao destacar que, quando se deu a criação das Faculdades de Letras de Lisboa e de Coimbra, em 1911, não havia em seus currículos "nenhuma cadeira de Literatura Brasileira (ou de Cultura Brasileira, ou de História do Brasil), que naturalmente também não constava do Curso Superior de Letras, a funcionar desde 1859".

A literatura brasileira circulou e circula no exterior, embora não tanto quanto desejável. Podemos dizer que há a barreira da língua impedindo-lhe a inserção em outros países, e como fator correlativo, a falta de apoio institucional para promover sua presença no exterior, mesmo em Portugal, com quem compartilhamos a língua Portuguesa. Arnaldo Saraiva (2002, p.7), iniciou o artigo "A poesia brasileira em Portugal" destacando que "durante séculos, os poetas brasileiros não foram mais lidos e conhecidos no Brasil do que em Portugal”. As razões, para Saraiva, eram óbvias: “ou porque nasceram em Portugal, ou porque viveram e estudaram em Portugal, ou porque em Portugal eram editados e em Portugal circulavam até em manuscritos". Tendo tratado da presença da poesia brasileira em Portugal ao longo dos séculos, no final do artigo, ressaltava que ficava provado que "a poesia brasileira do século XX foi chegando a Portugal, mas não decerto de modo sistemático [...] Nenhum livreiro ou

\footnotetext{
1 Dicionário de historiadores portugueses. GENTIL, Georges Le. (Fère-Champenoise, 1875 - Paris, 1853). Disponível em http://dichp.bnportugal.pt/imagens/gentil.pdf?fbclid=IwAR3yz2ypLqjEwmWe6ufrQ7yQ6ZgeOeTlAWjNOIcEP7bMV wfiFvysWybq9c Último acesso em 12 nov. 2020.
}

Gláuks: Revista de Letras e Artes -jul/dez $2020-$ Vol. 20, $N^{o} 2$ 
editor, e nenhuma instituição, pública ou privada, portuguesa ou brasileira, trabalhou razoável ou continuamente para circulação em Portugal dos poetas ou da poesia brasileira” (p.13).

O prejuízo decorrente dessa presença tímida da literatura brasileira no exterior é grande para os escritores, para os leitores, para a divulgação da cultura brasileira. Com frequência, os escritores brasileiros, quando são lidos no exterior, são recebidos por um repertório estrangeiro que não dialoga de modo mais amplo com a literatura brasileira. Não se trata de bairrismo, posto que, como disse o escritor Milton Hatoum, ao ser perguntado sobre as diferentes recepções de sua obra no exterior: "Cada país tenta relacionar o livro traduzido com a sua cultura". No entanto, Hatoum também destacou que deve "muita coisa à leitura de obras de Machado de Assis, Graciliano Ramos, Guimarães Rosa, Drummond, Bandeira, mas poucos jornalistas literários estrangeiros têm familiaridade com a obra desses autores. Então eles escrevem uma impressão de leitura a partir do repertório deles, como se Machado não existisse. E o diabo é que eu não teria escrito o Dois irmãos sem a leitura de Esaú e Jacó" (HATOUM, 2020, Apud NUNES FILHO, p.25).

É certo que a literatura brasileira, desde sua origem, não esteve circunscrita aos limites do território brasileiro. As formas de investigar esse aspecto são variadas e muitas delas requerem pesquisas em acervos e instituições brasileiras e estrangeiras. Pensando sobre esse e outros assuntos que envolve a circulação da literatura brasileira no exterior, quando lançamos a chamada do presente dossiê, tínhamos por objetivo acolher contribuições de estudiosos que trabalharam ou trabalham com a literatura brasileira no exterior em abordagens críticas, didáticas, historiográficas, tradutológica, editorias, etc. As motivações para a presente proposta eram variadas, mas destacávamos, em especial, o interesse por acompanhar a difusão da cultura e da literatura brasileira no exterior, sobretudo no presente, quando as áreas de Ciências Humanas, Letras e Artes no Brasil são mais afetadas pela falta de apoio institucional para realização de pesquisas e intercâmbios acadêmicos. Ressaltávamos a necessidade de políticas públicas consistentes de apoio à difusão da literatura brasileira no exterior, para o reconhecimento internacional do Brasil e para os estudiosos da literatura, em especial, os estudiosos da literatura comparada, pois, como observou o professor Earl Fitz (2012, p.25), da Vanderbilt University, em artigo sobre a recepção de Machado de Assis nos Estados Unidos: 
"quem trabalha com literatura brasileira conhece bem a dinâmica tradicional da influência, já que a maioria de nós passou a carreira lidando com a influência que outros autores, fossem eles da França, da Inglaterra ou dos Estados Unidos, exerceram sobre os brasileiros". Mais raros são os estudos sobre a influência que autores brasileiros exerceram sobre escritores de outras culturas e tradições. Para que isso ocorra com mais frequência, é imprescindível a divulgação da literatura brasileira no exterior, contando com trabalhos de pesquisadores, tradutores, editores etc.

Com o dossiê "A literatura brasileira no exterior" pretendíamos oferecer um recorte importante da circulação da literatura brasileira no exterior, visando contribuir para a realização de diálogos frutíferos entre estudiosos da literatura brasileira situados em diferentes contextos culturais. Agora, no momento de publicarmos os resultados de nosso trabalho, consideramos que obtivemos êxito. O volume está dividido em três seções: "Ensaios", "Artigos" e "Entrevistas". Abrimos a seção "Ensaios" com o trabalho "The Reception of Machado de Assis and Clarice Lispector in the United States and Beyond", do professor Earl Fitz (Vanderbilt University), sobre a recepção da literatura brasileira nos Estados Unidos e em outros países, enfocando, em particular, a obra dos escritores Machado de Assis e Clarice Lispector. Na sequência, temos o trabalho do professor Ettore Finazzi-Agrò (Sapienza Universidade de Roma), intitulado "A natureza (do/e o) animal: ambiente e mundo na obra de João Guimarães Rosa", um ensaio interessante sobre subjetividade e espaço no conto "Meu tio o Iauaretê”. O próximo ensaio, do professor Ferenc Pál (Eötvös Loránd University), intitula-se "Sobre a divulgação e recepção da literatura brasileira na Hungria" e traça um panorama da presença da literatura brasileira na Hungria a partir dos verbetes das enciclopédias editadas na viragem dos séculos XIX e XX até as traduções mais recentes, que abrem novas possibilidade de leitura da literatura brasileira no exterior. Completa essa seção o ensaio "Mar de longo: um Porto para a literatura brasileira", do professor Francisco Topa, da Universidade do Porto, com um balanço reflexivo sobre trinta anos de sua prática de investigação e ensino de literatura brasileira em Portugal.

Abrimos a segunda seção, "Artigos", com o trabalho intitulado "Clarice Lispector e a crítica italiana", da professora Letícia Valandro (Università degli Studi di Verona), sobre a 
recepção crítica da obra de Lispector, desde a primeira monografia publicada no país até a publicação de Storia della letteratura brasiliana (1997), da historiadora Luciana Stegagno Picchio, e de artigos em revista especializadas. Na sequência, temos o artigo "A introdução e recepção da Escrava Isaura na China”, dos professores Zhihua Hu (Zhejiang International Studies University/China), e da professora Maria Teresa Roberto (Universidade de Aveiro), permitindo-nos observar a inserção da literatra brasielira no exterior como consequência de uma inserção maior da telenovela brasielira. O próximo artigo, "Nós e os outros: autonomia e recepção na autotradução de João Ubaldo Ribeiro", da professora Sarah C. Lucena (Georgetown University), investiga as estratégias autotradutórias usadas pelo escritor João Ubaldo Ribeiros na tradução se seu romance Viva o Povo Brasileiro, analisando também a recepção anglófona da obra.

A terceira seção, "Entrevistas", é iniciada com Leonardo Tonus, professor de Literatura Brasileira na Sorbonne Université, pesquisador, escritor e tradutor. Perguntamoslhe sobre sua experiência como promotor da literatura brasileira no exterior por meio de iniciativas como a do festival Printemps Littéraire Brésilien, criado em 2014 e adiado em 2020 por causa da pandemia do Coronavírus. Na sequência, entrevistamos Felipe Lindoso, jornalista, tradutor, editor e consultor de políticas públicas para o livro e a leitura, a quem fizemos perguntas sobre o texto "As dificuldades de internacionalização da literatura brasileira", de sua autoria, o blog "O Xis do problema" e o trabalho de curadoria do projeto “Conexões Itaú Cultural - Mapeamento Internacional da Literatura Brasileira”.

Quando elaboramos o plano para a publicação de um dossiê dedicado ao tema "A literatura brasileira no exterior", ainda não tínhamos sido assolados pela pandemia do Covid19. A chamada de trabalhos $\mathrm{e}$ as perguntas para os entrevistados foram elaboradas previamente e enviadas antes de entramos em isolamento social. Fizemos sete perguntas e enviamos para uma lista de escritores brasileiros. O Covid-19 chegou e muita coisa pareceu desimportante diante da tragédia que passamos a enfrentar cotidianamente. Muitas de nossas atividades passaram a ser realizada à distância e pelo computador e, possivelmente, muita coisa será feita desse modo daqui para frente. Apesar das incertezas em que nos encontramos, levamos o trabalho adiante e os entrevistados que nos responderam, expressaram, cada um a 
seu modo, aspectos das calamidades que temos vivido nesse ano de 2020. As perguntas enviadas aos escritores foram:

1. Prezado(a) somos muito gratos a você por nos conceder essa entrevista para o presente dossiê da Gláuks dedicado ao tema "A literatura brasileira no exterior". Para iniciarmos, pedimos que nos fale sobre como é escrever e publicar literatura no Brasil.

2. Você considera que há diferenças que mereçam ser destacadas entre a recepção que sua obra tem no Brasil e a que tem no exterior?

3. Qual a importância da tradução, sobretudo, para o escritor que escreve em português?

4. Quais são os desafios para ser publicado(a) no exterior ou ser traduzido(a) para outra língua?

5. "Traduttore, traditore". Como é ler sua obra em outro idioma? Poderia nos dar algum exemplo?

6. Existe uma "literatura nacional", presa a um país, a uma região, a uma língua?

7. Seu fazer literário busca responder a alguma urgência presente na realidade social brasileira que você gostaria de destacar?

Na seção "Entrevistas", seguindo a ordem alfabética, encontram-se as respostas às perguntas que recebemos de Adriana Lisboa, Alexandre Vidal Porto, Goodofredo Neto, João Paulo Cuenca, Luiz Ruffato, Marcelo D'Salete, Marcos Siscar, Miriam Alves, Noemi Jaffe e Paulo Lins. São escritores brasileiros que circulam em livros e fisicamente por diferentes países. Alguns viveram, outros vivem no exterior, visitam o exterior para ministrar palestras, falar de literatura, trabalhar... Alguns também são tradutores e, enfim, todos são escritores de um mundo globalizado em constante e acelerada transformação.

Chegando ao final do trabalho, agradecemos a todos que atenderam a nossa chamada, professores, pesquisadores, editores e escritores, tradutores. Contamos também com o importante trabalho de dois discentes, Lais Moreira de Oliveira, graduanda do curso de Letras da Universidade Federal de Viçosa, e Luis Gustavo de Paiva Faria, mestrando do Programa de 
Pós-graduação em Letras da mesma instituição. Nosso muito obrigado a eles e aos assessores editoriais da Revista Gláuks, Marciana A. H. Pena Gonçalves e Márcio Fernandes da Silva.

Estamos nos aproximando do final do ano de 2020. Que possamos vencer a pandemia e seguir lendo, trabalhando, aprendendo, descobrindo, vivendo, inventando...

\section{Referências Bibliográficas}

FITZ, Earl. A recepção de Machado de Assis nos Estados Unidos durante as décadas de 1950 e 1960. Machado Assis Linha, Rio de Janeiro, v. 5, n. 9, p. 24-52, June 2012.

Available from $<$ http://www.scielo.br/scielo.php?script=sci_arttext\&pid=S198368212012 $000100003 \& \operatorname{lng}=$ en\&nrm=iso $>$. access on 12 Dec. 2020.

https://doi.org/10.1590/S1983-68212012000100003

NUNES FILHO, W. C.; MACHADO, L. Olhares sobre a literatura brasileira no exterior: uma entrevista com Milton Hatoum. Opiniães, [S. 1.], n. 13, p. 24-27, 2018. DOI: 10.11606/issn.2525-8133.opiniaes.2018.152841. Disponível em:

http://www.revistas.usp.br/opiniaes/article/view/152841. Acesso em: 12 dez. 2020.

SARAIVA, A. A poesia brasileira em Portugal. Terceira Margem, Porto, n. 3, p. 7-14. 2002. "Os estudos de literatura brasileira nas Universidades Portuguesas". Terceira Margem, Porto, n.2, p.7-17, 1999. 